\title{
Ischemic mitral regurgitation: Intraventricular papillary muscle imbrication without mitral ring during left ventricular restoration
}

L. Menicanti, MD

M. Di Donato, $M D^{b}$

A. Frigiola, $M D^{\mathrm{a}}$

G. Buckberg, $\mathrm{MD}^{\mathrm{c}}$

C. Santambrogio, $\mathrm{MD}^{\mathrm{a}}$

M. Ranucci, MD

D. Santo, MD

The RESTORE Group
From the Departments of Cardiac Surgery and Anesthesiology, Istituto Policlinico San Donato, San Donato Milanese, Milan, Italy, ${ }^{a}$ the Department of Critical Care Medicine, University of Florence, Florence, Ita$1 \mathrm{y},{ }^{\mathrm{b}}$ and the Department of Cardiac Surgery, University of California at Los Angeles School of Medicine, Los Angeles, Calif. ${ }^{c}$

Received for publication April 5, 2001; revisions requested May 11, 2001; revisions received Sept 25, 2001; accepted for publication Oct 31, 2001.

Address for reprints: Lorenzo Menicanti, MD, Istituto Policlinico San Donato, Via Morandi 30, San Donato Milanese, Milan, Italy (E-mail menicanti@libero.it).

J Thorac Cardiovasc Surg 2002;123: 1041-50

Copyright () 2002 by The American Association for Thoracic Surgery

0022-5223/2002 \$35.00+0 $\quad \mathbf{1 2 / 1 / 1 2 1 6 7 7}$

doi: $10.1067 / \mathrm{mtc} .2002 .121677$
Objectives: Functional mitral regurgitation in ischemic cardiomyopathy carries a poor prognosis, and its surgical management remains problematic and controversial. The aim of this study was to report the results of our surgical approach to patients who have had myocardial infarctions and have ventricular dilatation, mitral regurgitation, reduced pump function, pulmonary hypertension and coronary artery disease. This surgical approach consists of endoventricular mitral repair without prosthetic ring, ventricular reconstruction with or without patch, and coronary artery bypass grafting.

Patients: Forty-six patients (aged $64 \pm 10$ years) with previous anterior transmural myocardial infarction and mitral regurgitation comprised the study group. Indication for surgery was heart failure in $93 \%$ of cases; 25 patients were in New York Heart Association functional class IV and 17 were in class III. Mitral regurgitation was moderate to severe in 32 cases $(69 \%)$.

Results: All patients underwent coronary artery bypass grafting, with a mean of $3.2 \pm 1.3$ grafts. Associated aortic valve replacement was performed in 4 cases. Global operative mortality rate was $15.2 \%$. End-diastolic and end-systolic volumes significantly decreased after surgery (from $140 \pm 40$ to $98 \pm 36 \mathrm{~mL} / \mathrm{m}^{2}$ and from $98 \pm 32$ to $63 \pm 22 \mathrm{~mL} / \mathrm{m}^{2}$, respectively, $P=.001$ ). Systolic pulmonary pressure decreased significantly (from $55 \pm 13$ to $43 \pm 16 \mathrm{~mm} \mathrm{Hg}$, $P=.001)$. Ejection fraction did not change significantly. Postoperative mitral regurgitation was absent or minimal in $84 \%$ of cases; 1 patient had severe mitral regurgitation necessitating valve replacement. New York Heart Association functional class significantly improved. The mean preoperative functional class was $3.4 \pm 0.6$ (median 3, range 2-4); after the operation, this decreased to $1.9 \pm$ 0.7 (median 2, range $1-3, P<.001$ ). Cumulative survival at a 30 -month follow-up was $63 \%$.

Conclusions: Our aggressive, combined surgical approach is aimed at correcting the three components of ischemic cardiomyopathy: relieving ischemia, reducing left ventricular wall tension by decreasing left ventricular volumes, and reducing volume overload and pulmonary hypertension by repairing the mitral valve. Despite a relatively high perioperative mortality rate, surviving patients benefitted from the operation, with improved clinical functional class and thus quality of life. 


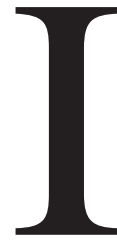

$\mathrm{n}$ the setting of large anteroseptal transmural myocardial infarction (MI) with severe cardiac dilatation (left ventricular [LV] remodeling), functional mitral regurgitation (MR) is linked to complex mechanisms not yet completely clarified. Among factors contributing to MR (annular dilatation, global and local remodeling), widening and lateral shift of papillary muscles play an important role in reducing leaflet coaptation. ${ }^{1-4}$

Surgical LV restoration associated with coronary artery bypass grafting is a technique that has recently been applied to postinfarction patients with dilated ventricles and depressed systolic function (Dor procedure) and that restores LV shape and improves pump function. ${ }^{5-7}$ Mitral repair or replacement is associated with $\mathrm{LV}$ reconstruction when needed; however, it is not well established which technique is most effective. ${ }^{8}$

At our center we have adopted an innovative technique to repair moderate to severe MR during the $\mathrm{LV}$ restoration procedure. It consists of reducing the mitral anulus and imbricating the papillary muscles without a prosthetic ring, approaching the valve through the ventricle through the same incision necessary to perform ventricular restoration. This aggressive approach to patients with postinfarction LV remodeling and associated MR (complete coronary revascularization, LV restoration, and mitral valve repair) is aimed at surgically correcting all three negative components of the pathologic condition: ischemia, LV remodeling, and volume overload, all of which are strictly linked with one another. In this article we report the results obtained in a group of 46 consecutive patients with a previous anterior MI, severe LV dysfunction, high functional class, MR, and pulmonary hypertension who underwent combined mitral valve repair, LV reconstruction, and coronary artery bypass grafting at San Donato Hospital, Italy.

\section{Patients and Methods}

Between December 1998 and December 2000, a total of 254 patients at our center underwent LV reconstruction for postinfarction cardiomyopathy. Two hundred thirty-three had anterior MI, 16 had posterior MI, and 5 had anterior plus posterior MI. One hundred forty-four of the 233 with anterior MI had preoperative MR of some grade (62\%); 46 of these had grade 2 or more MR and underwent mitral repair. These 46 patients were selected and represent the study group.

The mean age of these patients at surgery was $64 \pm 10$ years (range 38-80 years). There were 35 male and 11 female patients, and 26 patients were older than 65 years. Forty-three patients (93\%) had heart failure, with New York Heart Association (NYHA) functional class III or IV.

Clinical, surgical, perioperative, and predischarge data were analyzed from patient charts, which were systematically reviewed. Follow-up information was obtained by telephone interview with the patient or referring cardiologist in March 2001.
TABLE 1. Clinical characteristics of the study group $(\mathbf{n}=$ 46)

\begin{tabular}{lc}
\hline Age (y, mean \pm SD) & $64 \pm 10$ \\
\hline Male/female ratio & $35: 11$ \\
\hline Delay from MI (mo, mean \pm SD) & $61 \pm 71$ \\
\hline NYHA functional class (mean \pm SD) & $3.4 \pm 1$ \\
\hline Type of anterior asynergy (No.) & \\
Dyskinetic & $9(20 \%)$ \\
Akinetic & $37(80 \%)$ \\
\hline Degree of MR (No.) & \\
Grade 2 & $14(31 \%)$ \\
Grade 3 & $7(14 \%)$ \\
Grade 4 & $25(55 \%)$ \\
\hline NYHA functional class (No.) & \\
Class IV & $25(54 \%)$ \\
Class III & $18(40 \%)$ \\
Class II & $3(6 \%)$ \\
\hline Delay from MI (No.) & $15(33 \%)$ \\
$<3$ mo & $19(41 \%)$ \\
$<12$ mo & \\
\hline
\end{tabular}

All patients underwent preoperative and predischarge postoperative (10-14 days) echocardiographic examinations. Echocardiographic measurements were obtained with a Vingmed echocardiograph (Vingmed Holdings AS, Oslo, Norway). LV dimensions were calculated from 2-dimensional echocardiograms in standard views; LV volumes and ejection fraction (EF) were calculated by using a modification of the Simpson method with two apical views.

MR was assessed with color flow Doppler; severity was graded as mild (1), moderate (2), moderate to severe (3), or severe (4). Systolic pulmonary pressure was measured by Doppler tricuspid regurgitation velocity.

Clinical characteristics of the patients are shown in Table 1. All patients had moderate to severe MR; $55 \%$ had grade $4 \mathrm{MR}$. Ninety-four percent of patients were in NYHA functional class III or IV. In almost $40 \%$ of the cases, anterior MI was recent $(<12$ months previously), and in 15 cases it had occurred less than 3 months previously. The main indication for surgery was heart failure; $54 \%$ of the patients were in NYHA functional class IV. Angina alone was an indication for surgery in a few cases.

\section{Surgical Procedure}

Standard cardiopulmonary bypass was used with moderate hypothermia $\left(30^{\circ} \mathrm{C}\right)$. The aorta was crossclamped, and myocardial protection was achieved with topical hypothermia and crystalloid antegrade cardioplegia. More recently, a warm blood cardioplegia has been introduced.

After complete coronary revascularization had been performed, the LV was opened from the apex to the middle part, with an incision parallel to the left anterior descending artery, just over the necrotic or scarred area. The cavity was carefully inspected, and any thrombi were removed. Papillary muscles were identified, and the mitral valve was carefully checked (Figure 1). The right fibrous trigone was visualized, and a 2-0 polyester double-armed suture with a pledget was applied from the ventricular side to atrial side; 

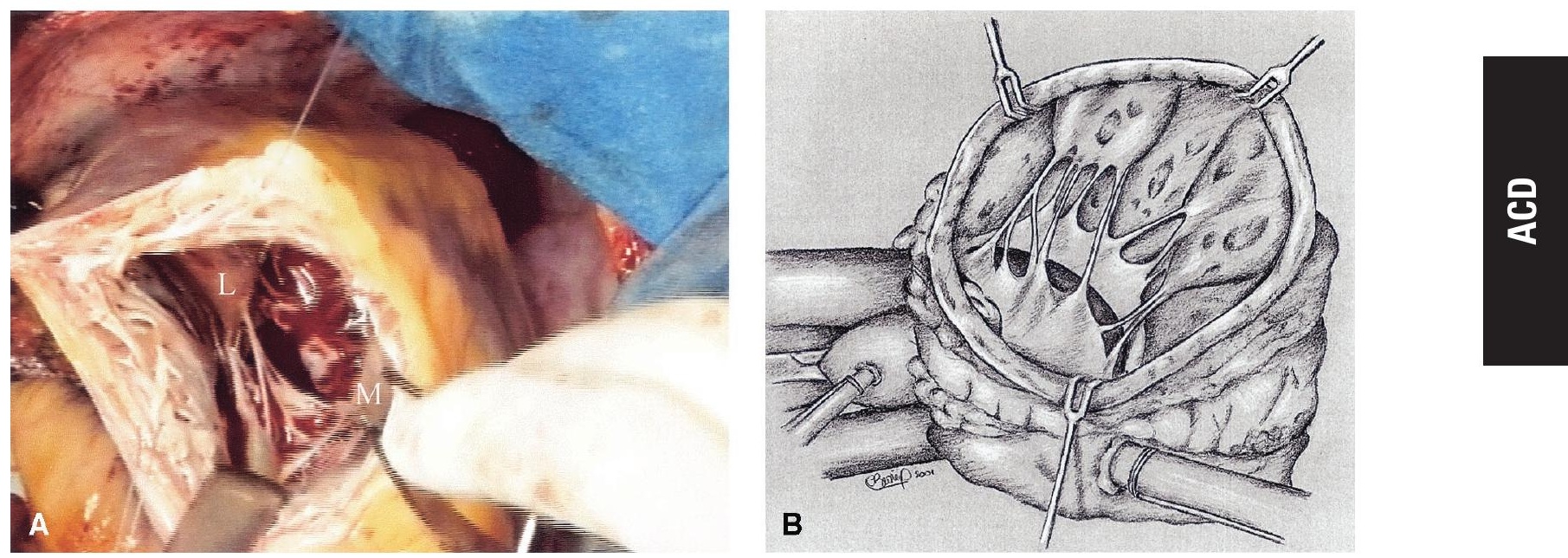

Figure 1. A, Mitral valve and papillary muscles viewed from left ventriculotomy. B, Schematic drawing of this view. $\boldsymbol{L}$, Anterolateral papillary muscles; $\boldsymbol{M}$, posteromedial papillary muscles.
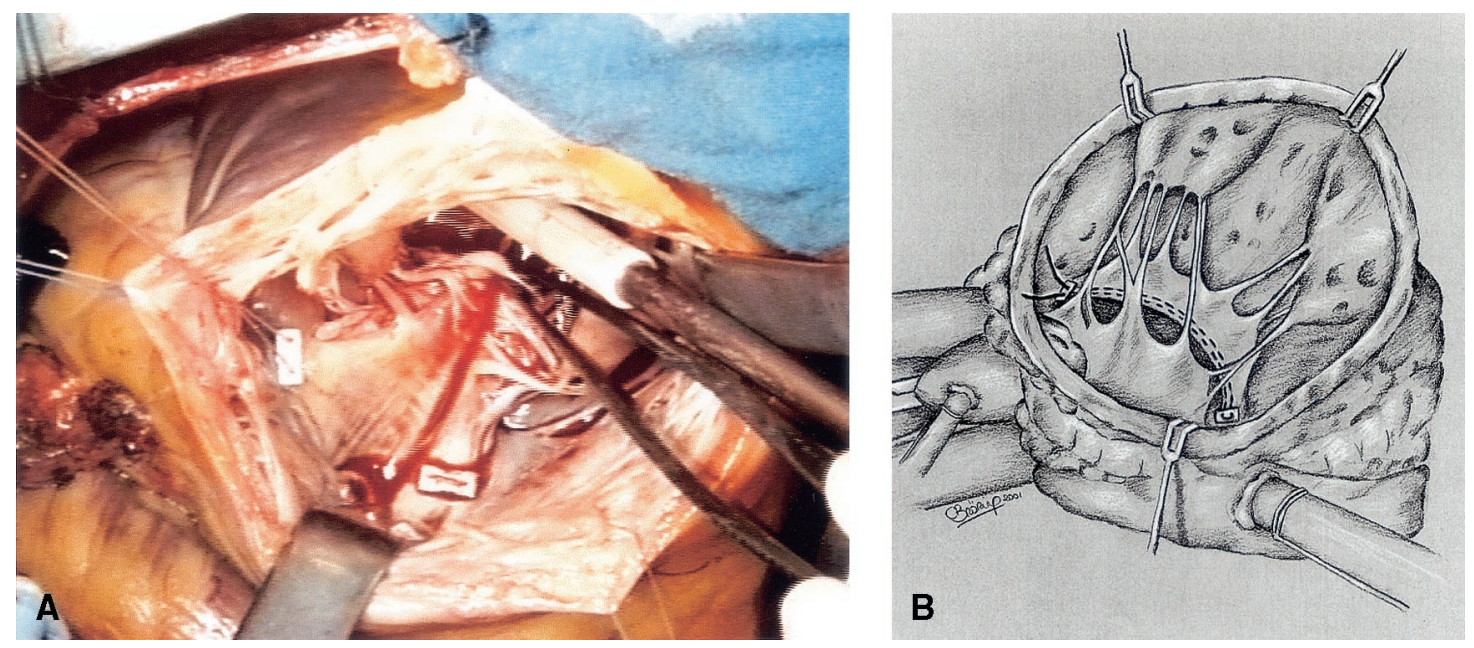

Figure 2. A, From left ventriculotomy two pledgets, applied at right and left trigones and anterior mitral leaflet, are shown. B, Two arms of stitch with running suture that completely bounds the posterior anulus are seen in schematic drawing.

the two arms of this stitch with a running suture were conducted toward the left trigone. The stitch ran a few millimeters from the mitral anulus biting atrial and ventricular muscle. The posterior anulus was completely bounded by this suture. The left trigone was reached, and the two arms of the suture were conducted from the atrial side to the ventricular side through the trigone just below the aortic valve (Figure 2). A 23-mm sizer was introduced into the mitral valve to create an undersized orifice but leave a surface area bigger than $3 \mathrm{~cm}^{2}$, and the suture was tied over a second pledget (Figure 3, A). Then the ventricular restoration was performed. The transitional zone between the healthy muscle and the infarcted zone was identified, and a 2-0 Prolene purse-string suture (Ethicon, Inc, Somerville, NJ) was applied. This encircling stitch differed slightly from the classical Fontan stitch in that it was close to the base of the papillary muscles and angulated in respect to the septum. In fact, the position and the orientation of this suture are crucial, because the orientation determine the residual shape and volume of the ventricle. The suture started from the apex of the LV and then proceeded into the middle part of interventricular septum, continuing toward the aortic valve. At a few centimeters from the aortic valve, the suture was conducted in the anterior and lateral wall, close to the bases of the papillary muscles, and then reached the LV apex (Figure 3, B). In this way the plan of the purse-string suture was as orthogonal as possible to the mitral plane, allowing a more elliptical, and thus more physiologically relevant, final shape. The purse-string suture was snared, and the bases of the two papillary muscles were imbricated, thus reducing the distance between them and also the volume of the LV cavity (Figure 3,C). 

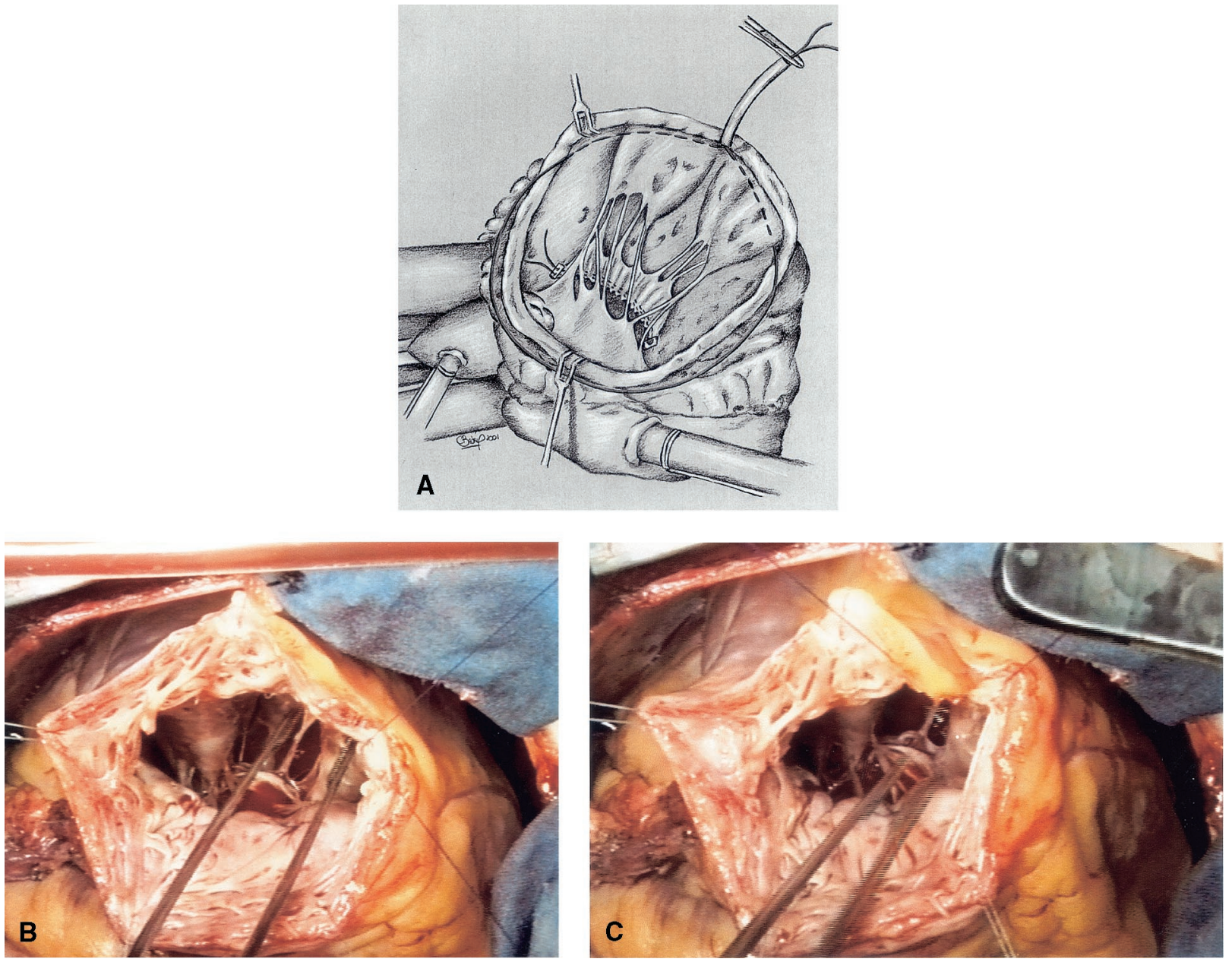

Figure 3. A, Suture is snared, reducing posterior anulus. B, Purse-string suture is applied in transitional zone at base of two papillary muscles. C, Distance between papillary muscles is markedly reduced when suture is snared.

The residual dimension of the cavity after securing the circumferential suture is a vital component of the procedure, because the risk of leaving too small a dimension actually exists. This problem was obviated by the introduction of a balloon sizer, as described by Dor and colleagues, ${ }^{6,7}$ which guides the suture closure and leaves a ventricular volume that is not restrictive. We inflated the balloon at $60 \mathrm{~mL}$ times the body surface area. Ventricular closure was then accomplished with or without a patch. A patch was selected if the residual neck was greater than $3 \mathrm{~cm}$ (Figure 4); direct suture was performed if the neck was smaller. The technique allows a reduction of both longitudinal and transverse dimensions, thus keeping LV volume and shape near normal (Figure 5).

\section{Statistical Analysis}

Data are reported as mean \pm SD (continuous variables), as median and range (discrete variables), or as absolute count and percentage (binary variables). Paired and unpaired $t$ tests, the Mann-Whitney $U$ test, the Pearson $\chi^{2}$ test, and relative risk analysis tests were used as appropriate. Variables that resulted in significance in the univariate analysis were tested in a multivariate logistic regression analysis to assess predictors of mortality.

\section{Results}

Operative data are reported in Table 2. Most patients had the LV reconstructed without a patch. All patients had multivessel grafting, with a mean of $3.2 \pm 1.3$ distal anastomoses. The mitral valve was repaired through the LV cavity in all cases. Aortic valve replacement was associated in 4 cases. An intra-aortic balloon pump was placed in 15 patients at the completion of the procedure, because we prefer the use of intra-aortic balloon pump when patients need a high level of inotropic support.

Table 3 reports preoperative and early postoperative hemodynamic results. Great and significant reductions in enddiastolic and end-systolic volumes were observed after surgery (Figure 2). Overall, EF did not change significantly. Twenty-six patients had a significant increase in EF, whereas 4 had no changes and 9 showed a slight reduction. Pulmonary artery pressure and end-diastolic diameter both decreased significantly.

Overall, operative mortality was $15 \%$. Postoperative MR 

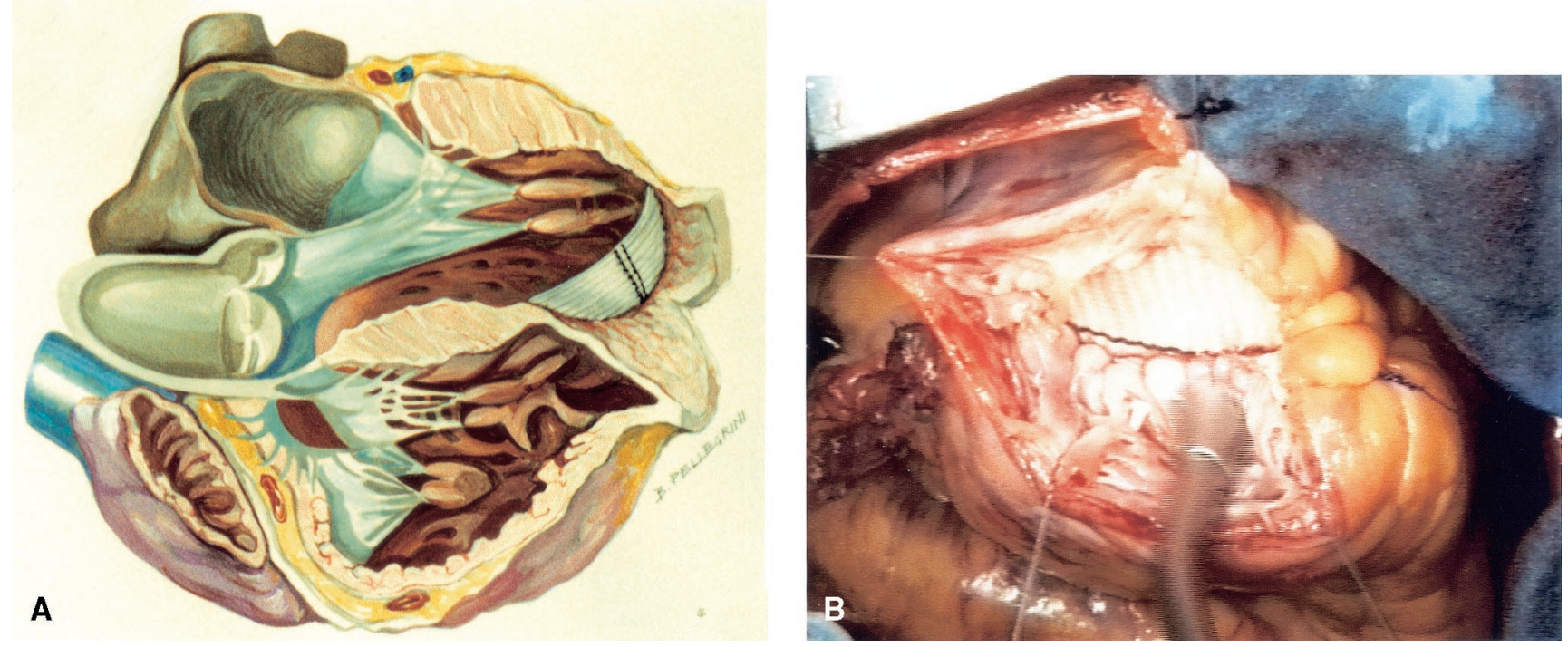

Figure 4. A, Schematic drawing of Dor procedure. Note excluded tissue and patch positioning toward septum with oblique orientation. B, Patch as it appears at completion of suture within cavity.

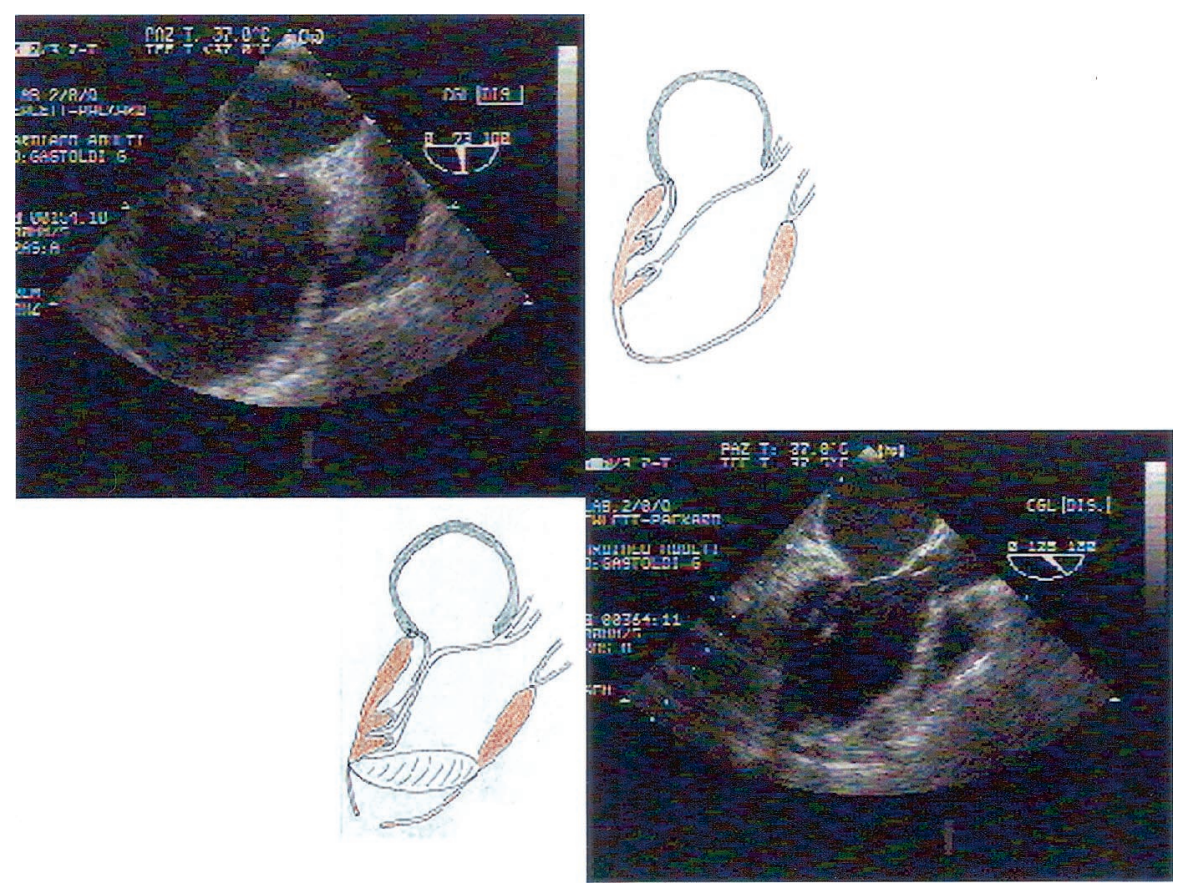

Figure 5. Transesophageal echocardiographic views and respective drawings are shown. A, Before surgery. LV cavity is rounded, papillary muscles are laterally displaced. Anulus is dilated, posterior muscle is retracted, and coaptation point is lost. B, After surgery. LV cavity is more elliptical in systole, anulus is reduced, and two papillary muscles are closer. Patch is positioned at base of papillary muscles and oriented obliquely toward aorta. Leaflet coaptation point is regained.

was absent or minimal in $84 \%$ of patients; it was severe in 1 patient, necessitating mitral valve replacement (Table 4). In this patient a recurrent severe valvular insufficiency appeared few days after surgery. The patient successfully underwent mitral valve replacement. During reintervention, a tear of the posterior leaflets, caused by a wrong passage of the semicircular suture into the leaflets itself, was found.

The follow-up analysis results (Figure 6) showed a 30- 


\section{TABLE 2. Operative variables}

\begin{tabular}{lc}
\hline Reoperation & $2(4 \%)$ \\
Urgent procedure & $2(4 \%)$ \\
No patch & $36(78 \%)$ \\
Dacron polyester fabric patch & $10(22 \%)$ \\
Left anterior descending coronary artery & $45(98 \%)$ \\
$\quad$ revascularization & \\
Circumflex coronary artery revascularization & $34(74 \%)$ \\
Right coronary artery revascularization & $32(69 \%)$ \\
Left internal thoracic artery graft & $43(93 \%)$ \\
Venous graft & $41(89 \%)$ \\
Distal anastomoses (mean \pm SD) & $3.2 \pm 1.3$ \\
Aortic valve replacement & $4(8 \%)$ \\
Need for intra-aortic balloon pump* & $16(35 \%)$ \\
Aortic crossclamp time (min, mean \pm SD) & $59.7 \pm 17$ \\
Cardiopulmonary bypass time (min, mean \pm SD) & $89.5 \pm 28$
\end{tabular}

*Only 1 patient had preoperative intra-aortic balloon pump implantation.

month cumulative survival of $63 \%$. The analysis was restricted to 30 months because of the limited number of patients with longer follow-up.

Mean NYHA functional class significantly improved after surgery (from $3.5 \pm 0.6$ to $1.9 \pm 0.7, P<.01$ ). No patient was in NYHA functional class IV, $82 \%$ of patients were in NYHA functional class I or II, and 6 patients were in NYHA functional class III (Table 5).

In Tables 6 and 7, we show the results of the univariate mortality (in-hospital) risk analysis for binary categoric and continuous variables. Only two factors were univariate predictors of in-hospital death: the presence of spontaneous ventricular tachycardia and the preoperative creatinine serum level. At the following stepwise multivariate logistic regression analysis, only the presence of spontaneous ventricular tachycardia remained an independent risk factor for in-hospital mortality (relative risk $13, P=.02$ ).

A late echocardiographic study (13 \pm 9 months) was available in 17 cases. Table 8 shows basal, early, and late postoperative echocardiographic parameters in this subset of patients. The improvement in LV volume was still significant at the late study, as were the annular size and the papillary muscle distance reduction. There was a slight progression of MR in 4 cases (from first to second degree), and MR was stable in 13 cases with respect to early postoperative study.

\section{Discussion}

The reported series consists of patients at very high risk (anterior Q-wave MI, severe LV dysfunction, high-grade $\mathrm{MR}$, and pulmonary hypertension) who underwent a complex surgical procedure (LV reconstruction, mitral repair, and associated coronary artery bypass grafting in all cases, with aortic valve replacement in 4).

\section{Anatomic and Functional Ventricular Alterations and Mechanisms of Functional Mitral Regurgitation in Ischemic Cardiomyopathy}

A large anteroseptal transmural MI determines a dilatation of the LV with elongation of the longitudinal and transverse diameters; this causes an abnormal orientation of the papillary muscles, with lateral displacement and increased forces toward the apex. The increase of the transverse diameter also leads to a widening of the two papillary muscles. In the normal heart, the transverse diameter is almost half the longitudinal one; when the heart dilates after an MI, the sphericity index (the ratio between the two diameters) approaches 1 .

When the shape of the ventricle approximates a sphere, the lateral wall tension increases and the fiber shortening is reduced. The papillary muscles are shifted and the posterior leaflet is pulled down, determining an increase of the tenting area and a decrease of leaflet coaptation (local remodeling). ${ }^{3}$

Functional MR therefore is seen in patients with normal mitral apparatus and frequently complicates ischemic cardiomyopathy. Its presence causes pulmonary hypertension and volume overload, which in turn potentiate LV dilatation. Annular dilatation, ventricular dilatation (global remodeling), and local remodeling are all factors that interplay in determining MR. ${ }^{3,9}$

\section{Mitral Valve Surgery}

Mitral valve surgery in ischemic and nonischemic cardiomyopathy potentially has the greatest benefits for patients with severely depressed pump function, but correction has not been routinely undertaken because of the presumed high operative mortality. This has made the management of such cases problematic and controversial; however, more recently some authors, ${ }^{10-13}$ and in particular Bolling and coworkers, ${ }^{14,15}$ have reported an improvement in symptomatic status and survival among patients with end-stage cardiomyopathy and severe MR, thus emphasizing mitral repair in end-stage cardiomyopathy as a new and effective strategy for these patients. Several different technique for reducing the mitral anulus have been reported since 1957, when Lillehei and coworkers ${ }^{16}$ reported the first procedure of anulus reduction. In ischemic MR, the results are more favorable to the mitral plasty with reduction of the posterior anulus without a prosthetic ring. ${ }^{13}$ Carpentier ${ }^{17}$ in 1969 introduced the concept of mitral ring replacement and completely changed the surgical approach to mitral valve. More recently, the idea that a rigid ring can interfere with the outflow tract determining gradients was introduced, and some concern arose about a decreased performance of the $\mathrm{LV}$. At present there is not conclusive evidence in the literature in favor or against a rigid ring, because a flexible ring can have only a marginal advantage in extreme situations. ${ }^{18,19}$ In more recent literature there has been a new 
TABLE 3. Preoperative and early postoperative echocardiographic variables

\begin{tabular}{lccc}
\hline & Preoperative & Postoperative & $P$ value \\
\hline Diastolic diameter $(\mathrm{mm})$ & $68 \pm 13$ & $61 \pm 14$ & .018 \\
Systolic diameter $(\mathrm{mm})$ & $56 \pm 13$ & $52 \pm 13$ & .13 \\
Fractional shortening & $19 \% \pm 8 \%$ & $17 \% \pm 9 \%$ & .19 \\
End-diastolic volume index $\left(\mathrm{mL} / \mathrm{m}^{2}\right)$ & $140 \pm 40$ & $94 \pm 27$ & .001 \\
End-systolic volume index $\left(\mathrm{mL} / \mathrm{m}^{2}\right)$ & $98 \pm 36$ & $63 \pm 22$ & .001 \\
EF & $30 \% \pm 7 \%$ & $33 \% \pm 10 \%$ & .11 \\
Mitral anulus systolic excursion & $8.7 \pm 2.3$ & $11.6 \pm 4.1$ & .09 \\
$\quad(\mathrm{~mm})$ & & $43 \pm 16$ & .001 \\
Systolic pulmonary artery pressure & $55 \pm 13$ & &
\end{tabular}

Data are mean $\pm S D$.

interest in different mitral valve repair techniques that avoid a prosthetic ring. ${ }^{20}$

In our patient population the reduction of the anulus is achieved without a prosthetic ring with a technique similar to that described by Shore, Wong, and Paneth, ${ }^{21}$ with the difference that we approach the valve through the LV, through the incision necessary to perform ventricular restoration. When the ventricle is enlarged the mitral valve can be exposed well from the ventricular cavity, and the two trigones are identified more easily than through the atrium. The mitral valve in these patients is absolutely normal; there are no signs of degenerative disease, and the fibrotic tissue of the trigones is strong enough to bear the tension of the annular stitch. Ventricular restoration with imbrication of the papillary muscles and reduction of ventricular volume further reduces the tension, stabilizing the shortening of the posterior anulus.

\section{Surgical Left Ventricular Reconstruction}

Dor and coworkers ${ }^{5,6,8}$ have extensively reported clinical and hemodynamic results of endoventricular circular patch plasty repair of the LV for postinfarction akinetic and dyskinetic scar. The technique, the Dor procedure, aims at restoration of LV geometry and fiber orientation and therefore represents an effort to attenuate negative LV remodeling in an attempt to improve survival and quality of life..$^{5,6,8}$ The technique has an acceptable operative mortality rate $(<10 \%)$, even for patients with preoperative LV dysfunction. Reported data show an improvement in global EF, a marked reduction of volumes, and a decrease of NYHA functional class, as well as an improvement in LV shape and geometry. The improvement in global pump function is due mainly to the increase in regional wall motion remote from the anterior scarred wall. ${ }^{22}$ Moreover, the procedure improves late survival ( $82 \%$ at 5 years), which is highly influenced by preoperative end-systolic volume index and clinical status. ${ }^{23}$

Overall, there was no significant change in EF after
TABLE 4. Early postoperative MR

\begin{tabular}{lcr}
\hline & No. $(\mathbf{n}=\mathbf{3 9})$ & $\%$ \\
\hline Presence of MR & & \\
Grade 4 & 1 & 3 \\
Grade 2 & 5 & 13 \\
Grade 1 & 23 & 59 \\
\hline Absence of MR & 10 & 25 \\
\hline
\end{tabular}

TABLE 5. Follow-up postoperative NYHA functional class

\begin{tabular}{lrr}
\hline Class & No. & $\%$ \\
\hline I & 12 & 31 \\
II & 20 & 51 \\
III & 6 & 15 \\
IV & 0 & 0 \\
\hline
\end{tabular}

surgery in our current series with MR. The lack of increase in $\mathrm{EF}$ is in contrast with the significant increase obtained by Bolling and colleagues ${ }^{14,15}$ in dilated nonischemic cardiomyopathy. However, our patients are different from those reported on by Bolling and colleagues ${ }^{14,15}$ in that they all had an anterior MI. It is difficult to characterize ventricular function in the setting of MR because of the reduction in afterload caused by mitral incompetence. Thus EF, like any other measure of systolic function, tends to overestimate the degree of function, and it is likely that in our patients the true degree of preoperative function was lower than was estimated by EF. In some studies EF has been reported to decrease after mitral surgery despite an improvement in end-systolic volume and a reduction of stress-volume ratio. ${ }^{24}$

In conclusion, our population with Q-wave LV anterior MI, marked ventricular dilatation, high grade of MR, pulmonary hypertension, high functional class, and severely depressed ventricular function had a poor prognosis, with 


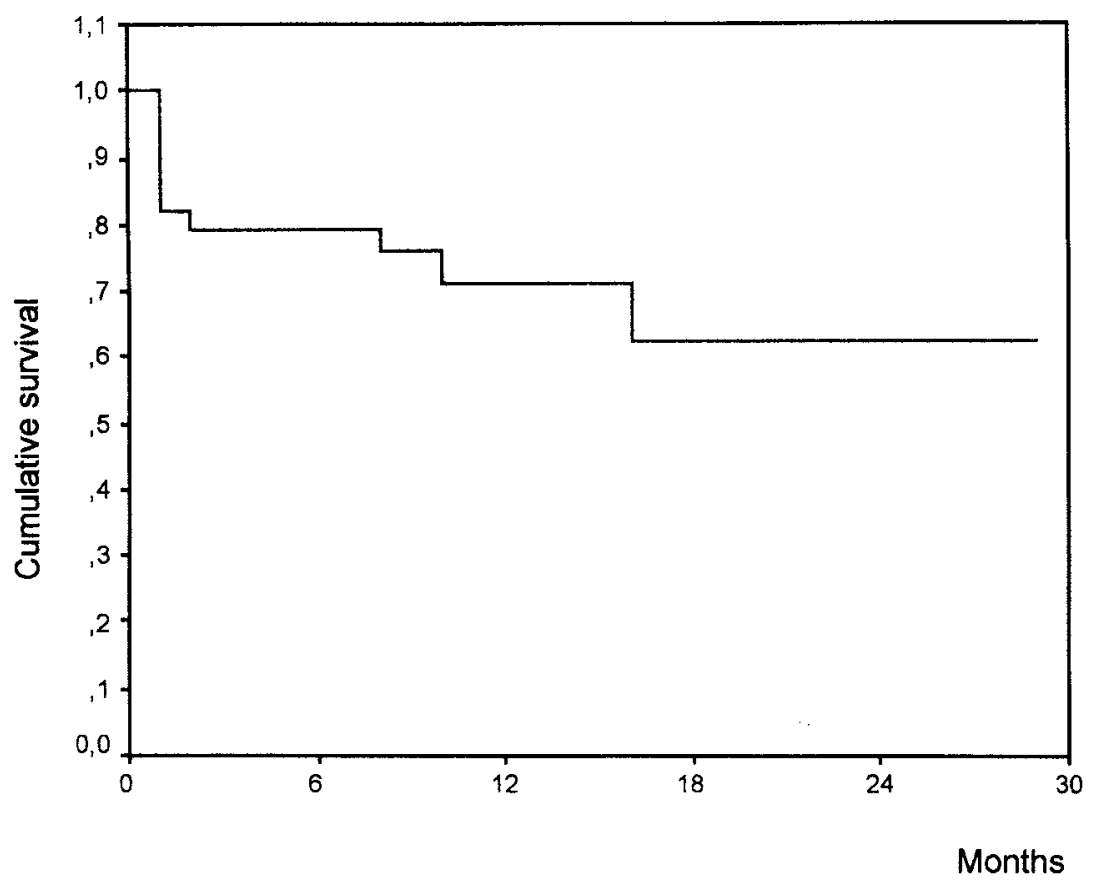

\begin{tabular}{rlllll}
$\begin{array}{l}\text { Time } \\
\text { (months) }\end{array}$ & $\begin{array}{l}\text { Number } \\
\text { of patients }\end{array}$ & $\begin{array}{l}\text { Number } \\
\text { of events }\end{array}$ & $\begin{array}{l}\text { Cumulative } \\
\text { proportion } \\
\text { surviving }\end{array}$ & $\begin{array}{l}\text { Variability } \\
\text { (SE) of the } \\
\text { estimates }\end{array}$ & $\begin{array}{l}\text { Hazard } \\
\text { rate }\end{array}$ \\
\hline & & & & & \\
6,0 & 39,0 & 8,0 &, 7838 & 0.067 &, 0404 \\
12,0 & 27,0 & 2,0 &, 7054 & 0.081 &, 0175 \\
18,0 & 11,0 & 1,0 &, 6270 & 0.103 &, 0196 \\
24,0 & 6,0 &, 0 &, 6270 & 0.103 &, 0000 \\
& 3,0 &, 0 &, 6270 & 0.103 &, 0000
\end{tabular}

Figure 6. Kaplan-Meier survival curve at $\mathbf{3 0}$ months.

extremely high risks for death and subsequent cardiac events. The aggressive combined surgical approach with $\mathrm{LV}$ reconstruction, complete coronary revascularization, and mitral valve repair tended to correct the three components of the disease by reducing $\mathrm{LV}$ tension, relieving ischemia, and reducing volume overload. Although a longer follow-up is mandatory, we believe that the innovative transventricular procedure for mitral repair without mitral prosthetic ring requirement is highly effective in relieving MR. It allows ventricular and mitral repair from the same approach and is therefore shorter. In our experience the trigones are better identified from the ventricular than from the atrial approach, and the posterior anulus potentiates the reduction of the transverse diameter obtained by volume reduction (by approaching the two papillary muscles) and thus contributes to a more physiologic correction of the LV shape, consequently leading to a better function.

We suspect that both the annular and the ventricular sutures are geometrically effective in reducing MR, especially when the encircling ventricular suture is correctly angulated in respect to the septum. The mitral anulus repair is perhaps the first mechanism that relieves volume overload, but the improved LV geometry is essential to maintain the efficacy of the repair. 
TABLE 6. Univariate mortality risk analysis for preoperative and intraoperative categoric variables

\begin{tabular}{|c|c|c|c|c|c|}
\hline Factor & $\begin{array}{l}\text { Survived } \\
(\mathrm{n}=39)\end{array}$ & $\begin{array}{l}\text { Died in hospital } \\
\quad(\mathrm{n}=7) \\
\end{array}$ & $\begin{array}{c}\text { Relative } \\
\text { risk }\end{array}$ & $\begin{array}{c}95 \% \text { Confidence } \\
\text { interval }\end{array}$ & $P$ value \\
\hline Female gender & 9 & 2 & 1.27 & $0.28-5.66$ & NS \\
\hline Smoking history & 23 & 4 & 0.93 & $0.18-4.7$ & NS \\
\hline Hypertension & 19 & 3 & 0.79 & $0.16-4.0$ & NS \\
\hline Diabetes & 20 & 3 & 0.71 & $0.14-3.61$ & NS \\
\hline Obesity & 3 & 0 & - & - & NS \\
\hline $\begin{array}{l}\text { Chronic obstructive } \\
\text { pulmonary disease }\end{array}$ & 10 & 4 & 3.8 & $0.73-20.3$ & NS \\
\hline Renal dysfunction & 11 & 4 & 3.4 & $0.66-17.6$ & NS \\
\hline Dyslipidemia & 13 & 4 & 2.6 & $0.52-13.7$ & NS \\
\hline $\begin{array}{l}\text { Peripheral vascular } \\
\text { disease }\end{array}$ & 10 & 4 & 3.8 & $0.73-20.3$ & NS \\
\hline $\begin{array}{l}\text { Spontaneous ventricular } \\
\text { tachycardia }\end{array}$ & 2 & 3 & 13.8 & $1.76-109$ & .02 \\
\hline Inotropic support & 5 & 2 & 2.7 & $0.4-18.0$ & NS \\
\hline Diuretic agents & 26 & 5 & 1.25 & $0.2-7.3$ & NS \\
\hline Vasodilatory agents & 35 & 6 & 0.67 & $0.06-7.2$ & NS \\
\hline Reoperation & 2 & 0 & - & - & NS \\
\hline $\begin{array}{l}\text { Preoperative intra-aortic } \\
\text { balloon pump }\end{array}$ & 0 & 1 & - & - & NS \\
\hline Urgent operation & 1 & 1 & 6.3 & $0.35-115$ & NS \\
\hline $\begin{array}{l}\text { Use of internal thoracic } \\
\text { artery }\end{array}$ & 36 & 7 & - & - & NS \\
\hline
\end{tabular}

$P$ values assigned according to Pearson $\chi^{2}$ test. $N S$, Not significant.

TABLE 7. Univariate mortality risk analysis for preoperative and intraoperative continuous variables

\begin{tabular}{|c|c|c|c|}
\hline Variable & $\begin{array}{l}\text { Survived } \\
(n=39)\end{array}$ & $\begin{array}{l}\text { Died in hospital } \\
\quad(n=7)\end{array}$ & $P$ value \\
\hline $\begin{array}{l}\text { Age }(\mathrm{y}) \\
\text { Body surface area }\left(\mathrm{m}^{2}\right) \\
\text { Creatinine }(\mathrm{mg} / \mathrm{dL}) \\
\end{array}$ & $\begin{array}{l}63.7 \pm 10.3 \\
1.77 \pm 0.17 \\
1.52 \pm 0.84 \\
\end{array}$ & $\begin{array}{l}67.4 \pm 6.6 \\
1.81 \pm 0.16 \\
2.23 \pm 0.89 \\
\end{array}$ & $\begin{array}{l}\text { NS } \\
\text { NS } \\
.049 \\
\end{array}$ \\
\hline $\begin{array}{l}\text { NYHA functional class } \\
\text { MR severity (degree) } \\
\text { LV diastolic diameter (mm) } \\
\text { LV systolic diameter (mm) } \\
\text { Shortening fraction } \\
\text { Septal thickness (mm) } \\
\text { Posterior wall thickness (mm) } \\
\text { LV end-diastolic volume (mL) } \\
\text { LV end-systolic volume } \\
\text { EF }\end{array}$ & $\begin{aligned} & 2.6 \pm 1.4 \\
& 3.2 \pm 0.96 \\
& 67.5 \pm 13.8 \\
& 56.2 \pm 14 \\
& 0.19 \pm 0.08 \\
& 12.9 \pm 10.1 \\
& 10.7 \pm 2.3 \\
& 248 \pm 84 \\
& 174 \pm 74 \\
& 0.3 \pm 0.07 \\
&\end{aligned}$ & $\begin{aligned} 2.4 & \pm 1.3 \\
3.1 & \pm 1.21 \\
68 & \pm 7.8 \\
54.6 & \pm 6.8 \\
0.19 & \pm 0.11 \\
13.2 & \pm 4.3 \\
11 & \pm 1.8 \\
221 & \pm 32 \\
160 & \pm 27 \\
0.28 & \pm 0.08\end{aligned}$ & $\begin{array}{l}\text { NS } \\
\text { NS } \\
\text { NS } \\
\text { NS } \\
\text { NS } \\
\text { NS } \\
\text { NS } \\
\text { NS } \\
\text { NS } \\
\text { NS }\end{array}$ \\
\hline Distal anastomoses & $3.2 \pm 1.3$ & $3.6 \pm 1.3$ & NS \\
\hline
\end{tabular}

Data are mean \pm SD.

TABLE 8. Echocardiographic data from the subset of patients with late control

\begin{tabular}{|c|c|c|c|c|}
\hline & Preoperative & Postoperative & $\begin{array}{c}\text { Late } \\
\text { postoperative }\end{array}$ & $\begin{array}{c}P \text { value } \\
\text { (vs basal) }\end{array}$ \\
\hline End-diastolic volume index $\left(\mathrm{mL} / \mathrm{m}^{2}\right)$ & $155 \pm 51$ & $98 \pm 29$ & $106 \pm 45$ & .0167 \\
\hline End-systolic volume index $\left(\mathrm{mL} / \mathrm{m}^{2}\right)$ & $105 \pm 48$ & $63 \pm 24$ & $68 \pm 37$ & .0331 \\
\hline EF & $32 \pm 5$ & $36 \pm 10$ & $38 \pm 9$ & .088 \\
\hline Papillary muscle distance (mm) & $40 \pm 7$ & $32 \pm 7$ & $33 \pm 5$ & .0053 \\
\hline Mitral anulus (mm) & $40 \pm 5$ & $24 \pm 4$ & $25 \pm 4$ & .0138 \\
\hline
\end{tabular}

Data are mean $\pm S D$. 


\section{References}

1. Lamas GA, Mitchell GF, Flaker GC, Smith SC, Gersh BJ, Basta L, et al. Clinical significance of mitral regurgitation after acute myocardial infarction. Survival and Ventricular Enlargement Investigators. Circulation. 1997;96:827-33.

2. Kaul S, Spotniz WD, Glasheen WP, Touchstone DA. Mechanism of ischemic mitral regurgitation: an experimental evaluation. Circulation. 1991;84:2167-80.

3. Yiu SF, Enriquez-Sarano M, Tribouilloy C, Seward JB, Tajik AJ. Determinants of the degree of functional mitral regurgitation in patients with systolic left ventricular dysfunction: a quantitative clinical study. Circulation. 2000;102:1400-6.

4. Kono T, Sabbah HN, Stein PD, Brymer JF, Khaya F. Left ventricular shape as a determinant of functional mitral regurgitation in patients with severe heart failure secondary to either coronary artery disease or idiopathic dilated cardiomyopathy. Am J Cardiol. 1991;68:355-9.

5. Di Donato M, Sabatier M, Montiglio F, Maioli M, Toso A, Fantini F, et al. Outcome of left ventricular aneurysmectomy with patch repair in patients with severely depressed pump function. Am J Cardiol. 1995 76:557-61.

6. Dor V, Sabatier M, Di Donato M, Montiglio F, Toso A, Maioli M. Efficacy of endoventricular patch plasty in large postinfarction akinetic scar and severe left ventricular dysfunction: comparison with a series of large dyskinetic scars. J Thorac Cardiovasc Surg. 1998;116:50-9.

7. Dor V, Saab M, Coste P, Kornaszewska M, Montiglio F. Left ventricular aneurysm: new surgical approach. Thorac Cardiovasc Surg. 1989;37:11-9.

8. Di Donato M, Sabatier M, Dor V, Gensini GF, Toso A, Maioli M, et al. Effects of Dor procedure on left ventricular dimension and shape and geometric correlates of mitral regurgitation one year after surgery. J Thorac Cardiovasc Surg. 2001;121:91-6.

9. Czer LS, Maurer G, Bolger AF, DeRobertis M, Chaux A, Matloff J. Revascularization alone or combined with suture annuloplasty for ischaemic mitral regurgitation: evaluation by color Doppler echocardiography. Tex Heart Inst J. 1996;23:270-8.

10. Bishay ES, McCarthy PM, Cosgrove DM, Hoercher KJ, Smedira NG, Mukherjee D, et al. Mitral valve surgery in patients with severe left ventricular dysfunction. Eur J Cardiothorac Surg. 2000;17:213-21.

11. Gangemi JJ, Tribble CG, Ross SD, McPherson JA, Kern JA, Kron IL. Does the additive risk of mitral valve repair in patients with ischemic cardiomyopathy prohibit surgical intervention? Ann Surg. 2000;231: $710-4$.
12. Smolens IA, Pagani FD, Bolling SF. Mitral valve repair in heart failure. Eur J Heart Fail. 2000;2:365-71.

13. Kay GL, Kay JH, Zubiate P, Yokoyama T, Mendez M. Mitral valve repair for mitral regurgitation secondary to coronary artery disease. Circulation. 1986;74:88-98.

14. Bolling SF, Pagani FD, Deeb GM, Bach DS. Intermediate-term outcome of mitral reconstruction in cardiomyopathy. $J$ Thorac Cardiovasc Surg. 1998;115:381-6.

15. Bolling SF, Deeb GM, Brunsting LA, Bach DS. Early outcome of mitral valve reconstruction in patients with end-stage cardiomyopathy. J Thorac Cardiovasc Surg. 1995;109:676-82.

16. Lillehei CW, Gott VL, Dewall RA, Varco RL. Surgical correction of pure mitral insufficiency by annuloplasty under direct vision. Lancet. 1957;1:446-9.

17. Carpentier A. La valvuloplastie reconstructive: une nouvelle technique de valvuloplastie mitrale. Presse Med. 1969;77:251-3.

18. Borghetti V, Campana M, Scotti C, Domenghini D, Totaro P, Pagani $\mathrm{M}$, et al. Biological versus prosthetic ring in mitral valve repair: enhancement of mitral annulus dynamics and left-ventricular function with pericardial annuloplasty at long term. Eur J Cardiothorac Surg. 2000;17:431-9.

19. von Oppell UO, Stemmet F, Brink J, Commerford PJ, Heijke SA. Ischemic mitral valve repair surgery. J Heart Valve Dis. 2000;1:64-73.

20. Duebener LF, Wendler O, Nikoloudakis N, Georg T, Fries R, Shafers HJ. Mitral-valve repair without annuloplasty rings: results after repair of anterior leaflets versus posterior-leaflet defects using polytetrafluoroethylene sutures for chordal replacement. Eur J Cardiothorac Surg. 2000;17:206-12.

21. Shore DF, Wong P, Paneth M. Results of mitral valvuloplasty with a suture plication technique. J Thorac Cardiovasc Surg. 1980;79:34957.

22. Di Donato M, Sabatier M, Toso A, Barletta G, Baroni M, Dor V, et al. Regional myocardial performance of non-ischaemic zones remote from anterior wall left ventricular aneurysm: effects of aneurysmectomy. Eur Heart J. 1995;16:1285-92.

23. Di Donato M, Sabatier M, Toso A, Maioli M, Dor V, Gensini GF, et al. Efficacy of Dor procedure on late survival in patients with postinfarction akinetic or dyskinetic scar and predictors of outcome. $J$ Am Coll Cardiol. 2001;Suppl:370A.

24. Timmis SB, Kirsh MM, Montgomery DG, Starling MR. Evaluation of left ventricular ejection fraction as a measure of pump performance in patients with chronic mitral regurgitation. Catheter Cardiovasc Interv. 2000;49:290-6. 